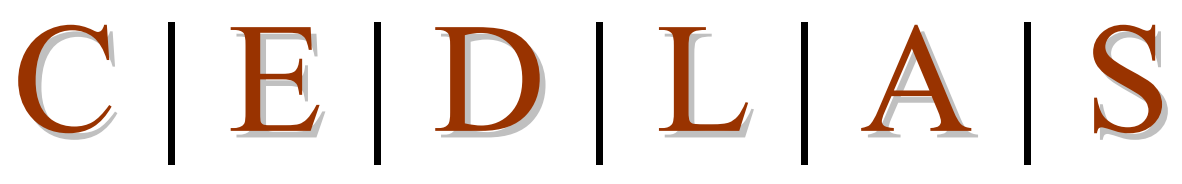

Centro de Estudios

Distributivos, Laborales y Sociales

Maestría en Economía

Facultad de Ciencias Económicas

Universidad Nacional de la Plata

\title{
The Heterogeneous Impact of Conditional Cash Transfers
}

\author{
Sebastian Galiani y Patrick J. McEwan
}

Documento de Trabajo Nro. 149

Septiembre, 2013

ISSN 1853-0168 


\title{
The heterogeneous impact of conditional cash transfers
}

\author{
Sebastian Galiani \\ University of Maryland \\ Patrick J. McEwan ${ }^{*}$ \\ Wellesley College
}

First version: July 2011

This version: April 2013

\begin{abstract}
The Honduran PRAF experiment randomly assigned conditional cash transfers to 40 of 70 poor municipalities, within five strata defined by a poverty proxy. Using census data, we show that eligible children were 8 percentage points more likely to enroll in school and 3 percentage points less likely to work. The effects were much larger in the two poorest strata, and statistically insignificant in the other three (the latter finding is robust to the use of a separate regression-discontinuity design). Heterogeneity confirms the importance of judicious targeting to maximize the impact and cost-effectiveness of CCTs. There is no consistent evidence of effects on ineligible children or on adult labor supply.
\end{abstract}

Keywords: Honduras; conditional cash transfers; education; child labor; randomized experiment.

\footnotetext{
* Corresponding author: pmcewan@wellesley.edu, Department of Economics, Wellesley College, 106 Central Street, Wellesley MA 02481, (781) 283-2987.
} 


\section{Introduction}

Conditional cash transfers (CCTs) have been extensively adopted in the last decade, especially in Latin America (Adato and Hoddinott, 2011; Fiszbein and Schady, 2009). The programs provide cash transfers to finance current consumption, but their receipt is conditional on behaviors such as regular school attendance or use of primary health services. Given the mounting evidence suggesting that households are constrained in their knowledge of the best course of action, social programs that encourage them to pursue desirable actions are potentially welfare enhancing (Banerjee and Duflo, 2011).

Randomized experiments in Latin America consistently find that poor, school-aged children eligible for a CCT are more likely to enroll in school and to complete more grades (Behrman and Parker, 2010; Fiszbein and Schady, 2009). ${ }^{1}$ The increased school attainment is accompanied by declines in child labor supply (Edmonds and Schady, 2012). ${ }^{2}$ This paper conducts a new analysis

\footnotetext{
${ }^{1}$ The Progresa experiment in Mexico showed short-run enrollment effects of less than one percentage point among primary children-with primary enrollment rates already exceeding 90\% - but 6-9 percentage points among secondary school children (Schultz, 2004; Behrman et al., 2005; Skoufias, 2005). Almost six years after the treatment, older children exposed to the education transfers gained 0.7-1 more grades in school, but with no effects on achievement tests (Behrman et al., 2010, 2011). The Nicaraguan RPS experiment found enrollment effects of 13 percentage points on primary-aged children after two years of exposure to treatment, with accompanying gains in attendance and grade advancement (Maluccio and Flores, 2005; Maluccio et al., 2010). In Ecuador, a CCT was randomly assigned to a treatment group of poor families, although administrative issues led nearly $42 \%$ of the control group to receive transfers (Schady and Araujo, 2008). Intention-to-treat estimates show that random assignment to the treatment group increased enrollment by 3 percentage points, and the instrumental variables estimates showed effects of 10 percentage points. Finally, a CCT targeted at poor urban adolescents in Bogotá increased attendance and re-enrollment in secondary school (BarreraOsorio et al., 2011).

${ }^{2}$ Skoufias and Parker (2001) found that Progresa reduced work among 12-17 year-old boys by 35 percentage points and 2 percentage points among girls. The Nicaraguan experiment found declines of 3-5 percentage points (Maluccio and Flores, 2005). In the Ecuadorean experiment, paid and unpaid work declined by 10 and 19 percentage points, respectively, among adolescents (Edmonds and Schady, 2012). Finally, the Colombian experiment found that hours worked declined by a third (Barrera-Osorio et al., 2011).
} 
of the impact of a Honduran CCT on child enrollment and work. Between 2000 and 2002, the Programa de Asignación Familiar (PRAF) implemented two cash transfers: (1) an education transfer of about US\$50 per year, for each child between 6 and 12 who enrolled in and regularly attended grades 1 to 4 ; and (2) a health transfer of about US\$40 per year for each child under 3 or pregnant mother who regularly visited a health center. Of 298 Honduran municipalities, a randomized experiment included 70 with the lowest mean height-for-age z-scores, a proxy of municipal poverty (IFPRI, 2000). The 70 municipalities were divided into 5 quintiles based on mean height-for-age, and 8 of 14 municipalities in each quintile were randomly selected to receive transfers. ${ }^{3}$

This paper uses the 2001 Honduran Census, rather than the official evaluation data. ${ }^{4}$ The census was conducted 8 months after the first transfer was distributed and just weeks after the second round of transfers. Using individual census data matched to municipal-level treatment data, we find that the Honduran CCT increases the enrollment of eligible children by 8 percentage points, a $12 \%$ increase over the control group enrollment rate. We further show that it decreases the proportion of children who work outside the home by 3 percentage points (or $30 \%$ ), and decreases the proportion who work inside the home by 4 percentage points (or 29\%). There is no evidence that full-sample treatment effects are biased, given balance across treatment

\footnotetext{
${ }^{3}$ Some municipalities were also assigned to receive direct investments in schools and health centers, but these were not implemented during the time of the official evaluation (Moore, 2008). ${ }^{4}$ Using the official evaluation data, Glewwe and Olinto (2004) analyze child school and work outcomes; we discuss their findings in section 5. Morris et al. (2004) analyze health outcomes, finding statistically significant effects of CCTs on the frequency of antenatal care, recent health center check-ups and growth monitoring. Measles and tetanus immunization were not affected. Stecklov et al. (2007) find that CCTs produced large increases in births or pregnancy in the past year (measured in 2002), which they attribute this to the per-capita health transfer for pregnant women and young children. Alzúa et al. (forthcoming) find no effects of CCTs on adult labor supply.
} 
and control groups in a range of observed individual and household variables not affected by the treatment.

Our paper makes several contributions to the CCT literature, facilitated by the large census samples. First, we exploit the stratified design to estimate treatment effects separately by experimental strata. The estimated effects on enrollment in the two poorest (or malnourished) strata are 18 and 10 percentage points, respectively. The effects on child work outside the home are 8 and 5 percentage points and, on work inside the home, 6 and 6 percentage points, respectively. Depending on the stratum, these represent percentage increases of $16-32 \%$ in enrollment, and decreases of $50-55 \%$ in work outside the home, and $38-46 \%$ in work inside the home. Strikingly, the effects in three richer (but still poor) strata are statistically indistinguishable from zero. To assess the robustness of the latter finding, we leverage the regression-discontinuity design implied by the formula used to select the 70 experimental municipalities. Though imprecise, the point estimates are consistent with the absence of effects in the "richest" stratum.

Other research tends to find larger effects on enrollment when eligible children are in poorer households. ${ }^{5}$ However, it is important to note that our main findings of treatment heterogeneity are based on a feature of the original stratified design, addressing concerns about potentially arbitrary subgroup analysis using experimental data (Deaton, 2010). Collectively, the results highlight the importance of carefully choosing proxy indicators to identify and target the poor (Coady et al., 2004; Alatas et al., 2012; and De Wachter and Galiani, 2006).

\footnotetext{
${ }^{5}$ For a review of theory and evidence, see Fiszbein and Schady (2009). For related empirical evidence, see Maluccio and Flores (2005), Filmer and Schady (2008), and Oosterbeek et al. (2008).
} 
Second, the paper finds no consistent evidence that children who are ineligible for education transfers (by virtue of having completed fourth grade) are affected by the municipal-level treatment, regardless of whether an eligible child lives in the same household. A modest improvement in enrollment occurs in just the poorest stratum, but this could be attributed to lax enforcement of grade-completion requirements for eligibility. The finding contrasts with the relatively large positive spillovers on secondary school enrollment of children in ineligible households in the Progresa experiment (Bobonis and Finan, 2008). ${ }^{6}$ It is important to note, however, that Progresa transfers were much larger: 27 percent of pretransfer consumption vs. 7 percent in Honduras (Fiszbein and Schady, 2009). We also find no evidence that CCTs affected adult female labor supply. A modest impact on adult male labor supply is confined to the two richer strata and is not replicated by the discontinuity design.

Third, and not least, the paper provides a rare opportunity to replicate the results of a social experiment using a new source of data. Using a household survey collected in late 2002, Glewwe and Olinto (2004) found that school enrollment in 2001 was 7 percentage points higher in municipalities treated with CCTs (see section 5.1). Unlike this paper's results, they found that child work was only 0.5 percentage points lower in CCT municipalities, and statistically insignificant. However, the confidence interval is consistent with reductions even larger than those reported in this paper. Alzúa et al. (forthcoming) also analyzed the household survey and, like this paper, found no effects on adult labor supply. Our paper is the first to consider the issue of heterogeneity across the experimental strata, as well as spillover effects on ineligible children.

Section 2 of the paper provides background on PRAF-II and the CCT treatment, as well as its randomized assignment. Section 3 describes features of the 2001 census data, while section 4

\footnotetext{
${ }^{6}$ Barrera-Osorio et al. (2011) find that untreated siblings in a Colombian program actually have lower attendance and enrollment.
} 
describes the empirical strategy. Section 5 describes the empirical results, and section 6 concludes.

\section{PRAF in Honduras}

\subsection{Background}

The Programa de Asignación Familiar (PRAF), or Family Allowances Program, started in the early $1990 \mathrm{~s}^{7}$ Its first phase, PRAF-I, distributed cash subsidies to families, including a Bono Escolar available to children in early primary school grades, and a Bono Materno Infantil available to pregnant mothers and families with young children. Subsidies were supposedly conditioned on regular school attendance and health center visits, and PRAF-I beneficiaries were identified by local civil servants, including teachers and health center employees. In practice, PRAF-I appears to have rarely enforced conditionalities, and the poverty targeting mechanism was applied haphazardly with substantial leakage to higher-income families (Moore, 2008). No credible impact evaluations were conducted.

In response to these shortcomings, PRAF-II was launched in the late 1990s with support from the Inter-American Development Bank (IDB). It aspired to improve on PRAF-I in several ways, including: (1) improved enforcement of conditionalities for subsidy distribution; (2) a renewed emphasis on direct investments in schools and health centers alongside the distribution of cash subsidies; (3) an improved poverty targeting mechanism; and (4) a randomized evaluation design embedded within the project roll-out (IFPRI, 2000; Glewwe and Olinto, 2004; Morris et al., 2004).

${ }^{7}$ For details on PRAF-I and its successors, see BID (2004) and Moore (2008). 


\subsection{PRAF-II Treatments}

PRAF-II implemented two kinds of cash transfers. The education transfer, in the amount of 800 Lempiras per year (about US\$50), was available to each child between 6 to 12 who enrolled in and regularly attended grades 1 to 4 between the school year of February to November. ${ }^{8}$ Children were not eligible if they had already completed fourth grade. A health transfer of 644 Lempiras per year (about US\$40) was available to children under 3 and pregnant mothers who regularly attended health centers. Households were eligible to receive up to 3 education transfers and up to 2 health transfers. In practice, Glewwe and Olinto (2004) report that education enrollment (but not attendance) was enforced as a conditionality. Although families regularly deposited health center attendance slips, no health beneficiaries were suspended for failure to attend health centers (Morris et al., 2004). During the two years of implementation, transfers were distributed in November 2000, May-June 2001, October 2001, and late 2002 (see Figure 1). The transfers were locally distributed as cash by PRAF personnel (Moore, 2008).

Just before PRAF-II was implemented, the median annual expenditure per capita of households in experimental municipalities was 3,846 Lempiras, which was well below the extreme poverty line of 6,462 Lempiras per year, or about US\$1.20 per day (IFPRI, 2000). The headcount ratio was $71 \%$. Using census data from 70 experimental municipalities, in concert with eligibility rules, we further estimated that the average household was eligible for 1,127 Lempiras annually, or 182 Lempiras per capita. ${ }^{9}$ This is only about $5 \%$ of the median per capita expenditure, on the low side of other CCT programs in the region. By way of comparison,

\footnotetext{
${ }^{8}$ Our description of the treatments relies on Morris et al. (2004). Other sources report very similar but not identical amounts for the demand-side transfers (Caldés et al., 2004; Glewwe and Olinto, 2004; IFPRI, 2000; BID, 2004).

${ }^{9}$ This may understate the amount because the census does not include data on one eligibility criterion: whether women are currently pregnant.
} 
Fiszbein and Schady (2009) calculate that CCT transfers in Honduras, Nicaragua, and Mexico are $7 \%, 29 \%$, and $22 \%$, respectively, of pretransfer consumption.

In addition to CCTs, PRAF intended to implement two kinds of direct investments in schools and health centers. The education interventions consisted of payments of approximately US\$4,000 per year, depending on school size, to parent associations in primary schools (Glewwe and Olinto, 2004). The payments were conditioned on obtaining legal status and preparing a quality-improvement plan. The health interventions consisted of payments of approximately $\$ 6,000$ per year to local health centers, depending on the client base (Glewwe and Olinto, 2004). The health payments were conditioned on the formation of a health team (with members of the community and health personnel) and the preparation of a budget and proposal. In fact, the distribution of education and health funds was extremely limited. By late 2002, only $7 \%$ and $17 \%$ of the education and health funds, respectively, were disbursed, and the formation of parent and community groups authorized to administer funds still faced legal hurdles (Moore, 2008).

\subsection{Experimental Sample and Random Assignment}

To identify the experimental sample, IFPRI (2000) ordered 298 municipalities from lowest to highest values of the mean height-for-age z-score of first-graders, obtained from the 1997 Height Census of First-Graders (Secretaría de Educación, 1997). Seventy-three eligible municipalities had z-scores below a cutoff of -2.304 . Of these, 3 were excluded because of distance and cost considerations, yielding a final sample of 70 municipalities, identified as the unshaded municipalities in Figure 2. The geographic concentration of child stunting produced a sample dominated by western Honduras. 
Three treatment groups and one control group are henceforth referred to as G1, G2, G3, and G4 ${ }^{10} \mathrm{G} 1$ was to receive CCTs in education and health. G2 was to receive CCTs in addition to direct investments in education and health centers, while G3 would receive only direct investments. G4 would receive no interventions. The 70 municipalities were divided into five quintiles of 14 municipalities, based on mean height-for-age. The random assignment occurred on October 13, 1999 during a public event (see Figure 1). Within each quintile, 4 municipalities were randomly assigned to G1, 4 to G2, 2 to G3, and 4 to G4. The final sample consisted of 20 municipalities in G1, 20 in G2, 10 in G3, and 20 in G4 (see Figure 2). As previously mentioned, there is evidence that the direct investments in G2 and G3 were not implemented during the first year.

\section{Data}

The 2001 Honduran Census was conducted between July 28, 2001 and August 4, 2001 in all 298 municipalities (República de Honduras, 2002). This occurred approximately 8 months into the first year of the PRAF-II treatment, after 2 of 3 transfer payments had occurred in G1 and G2 (see Figure 1). This paper uses the individual and household data, merged to municipal-level data on treatment group and strata membership.

Table A.1 defines three dummy dependent variables. The first variable, enrolled in school, indicates whether a child is enrolled in and attending school at the time of the census, more than halfway through 2001 school year. In this sense, it reflects initial enrollment as well as school drop-outs that may have occurred after enrollment but before the census. Two additional variables measure child labor supply in the week prior to the census. The first, work outside

${ }^{10}$ See IFPRI (2000), Glewwe and Olinto (2004), and Morris et al. (2004). 
home, indicates whether children worked during the previous week or-conditional on a negative response - whether they reported non-wage employment in a family farm or business. The second variable, work inside the home, indicates whether children worked exclusively on household chores. Given the flow of the census questionnaire, this variable does not capture inhome labor supply of children with any wage or non-wage employment outside the home.

The independent variables defined in Table A.1 include those unlikely to be affected over the duration of the treatment. They include common individual variables such as age and gender, in addition to a dummy variable indicating self-identification as indigenous (Lenca).${ }^{11}$ Household variables include parent education and literacy, household structure, dwelling quality, service availability, and presence of costly assets like autos and computers.

Table 1 reports descriptive statistics in samples of children eligible to receive education transfers - that is, children between 6 and 12 who have yet to complete fourth grade. (Both work variables are only available for children 7 and older, leading to slightly smaller sample sizes.) The initial columns confirm that eligible children in the 70 experimental municipalities are more disadvantaged than the national sample. They are more likely to be indigenous; their parents have lower levels of schooling, literacy, and wealth; and they live in lower-quality dwellings. The remaining columns of Table 1 compare variable means within municipalities assigned to treatment and control groups. For each independent variable, we fail to reject the null hypothesis that means are jointly equal across the four groups. ${ }^{12}$ In contrast, the means of dependent

\footnotetext{
${ }^{11}$ Unlike Guatemala and other countries in Central and South America, this does not imply monolingual or bilingual status in any indigenous language.

${ }^{12}$ We regress each independent variable on dummy variables indicating G1, G2, and G3 (and 4 out of 5 strata dummies), and cluster standard errors at the level of municipality. The $p$-value is from a F-test of the null that coefficients on G1, G2, and G3 are jointly zero.
} 
variables suggest higher enrollment rates and reduced work in G1 and G2, relative to G3 and G4. We reject the null hypothesis that the means are jointly equal at the 5 percent significance level.

\section{Empirical Strategy}

Given randomized assignment, the empirical strategy is straightforward. The initial specification is:

$$
O_{i j k}=\beta_{0}+\beta_{1} G 1_{j k}+\beta_{2} G 2_{j k}+\beta_{3} G 3_{j k}+\delta_{k}+\varepsilon_{i j k}
$$

where $O$ is the binary school or labor outcome of child $i$ in municipality $j$ in experimental block (or stratum) $k$. The regression function conditions on three dummy variables indicating treatment groups G1, G2, and G3, as well block dummy variables $\left(\delta_{k}\right)$. Henceforth, we refer to the quintile with the lowest mean height-for-age z-scores as block 1 , up to block 5 . Some specifications also control for a vector of child and household characteristics. We estimate the regressions by ordinary least squares, clustering standard errors by municipality. But recall evidence that the direct investments in G2 and G3 were not implemented, especially in the 2001 school year and even by the end of the two-year evaluation (Moore, 2008). Thus, we separately test null hypotheses that $\beta_{3}=0, \beta_{1}=\beta_{2}$, and $\beta_{2}=\beta_{3}$. We fail to reject the first two, and reject the third, leading us to prefer a simpler specification:

$$
O_{i j k}=\beta_{0}+\beta_{1} C C T_{j k}+\delta_{k}+\varepsilon_{i j k}
$$

where $C C T$ indicates children in the G1 or G2 experimental groups, relative to the pooled control group of G3 or G4. Subsequent specifications examine heterogeneity by: (1) interacting CCT with five experimental block dummy variables, to assess whether treatment effects vary by mean height-for-age; (2) interacting $C C T$ with child-specific variables such as age, gender, and a poverty proxy. Finally, we estimate equation (2) in two subsamples. To test for spillovers, we 
report estimates within the subsample of children between 6 and 12 who are ineligible because they have completed fourth grade. We also estimate equation (2) within subsamples of male and female adults, to assess whether there is an adult labor supply response to transfers.

\section{Results}

\subsection{Effects on Children Eligible for Education Transfers}

Table 2 describes the main experimental results. In panel A, column (1) shows that eligible students in the G1 and G2 experimental groups are, respectively, 10.1 and 7.4 percentage points more likely to attend school, relative to G4. The coefficient on G3 is small and statistically insignificant. Controlling for a full set of baseline variables in column 2 does not change the basic pattern of results: CCTs increase enrollments by $7-8.3$ percentage points, and direct investments appear to have no impact. In column (2), one cannot reject the null hypothesis that the coefficients on $\mathrm{G} 1$ and $\mathrm{G} 2$ are equal ( $p$-value $=0.63$ ), but one can reject the null that the coefficients on G2 and G3 are equal ( $p$-value $=0.06$ ). Collectively, the evidence does not suggest that putative investments in G2 or G3 affected enrollments. Similar patterns are evident for child work variables in columns (4) and (6).

Thus, the regressions in panel B include a single dummy variable, $C C T$, indicating that the child resides in a G1 or G2 municipality. Conditional on individual and household variables, the enrollment of eligible children living in G1 or G2 increases by 8 percentage points (see column (2)). Columns (4) and (6) provide similar evidence for indicators of child work (the sample sizes are smaller because the census excluded 6 year-olds from work-related questions). Overall, eligible children in treated municipalities are 3 percentage points less likely to work outside the home and 4 percentage points less likely to work exclusively on household chores inside the 
home. The magnitude of these estimates is substantial. In the control group, $65 \%$ of eligible children are enrolled in school, $10 \%$ work outside the home, and 14\% work inside the home (see Table 3). Thus, in the full sample of eligible children, the cash transfer increases enrollment by $12 \%$, reduces work outside the home by $30 \%$, and reduces work inside the home by $29 \%$.

The full-sample results are consistent with data from a follow-up household survey carried out between May and September 2002 (Glewwe and Olinto, 2004). ${ }^{13}$ In the sample of 6 to 12 year-olds, the 2001 enrollment rate — reported retrospectively—is 7.0 percentage points higher in municipalities treated with CCTs (with a standard error of 2.3) ${ }^{14}$ The difference (standard error) for 2002 enrollments is 5.2 (2.4) percentage points, while the difference (standard error) in the proportion of children who worked in the week prior to the household survey is -0.5 (1.7) percentage points.

The estimates from Glewwe and Olinto (2004) include all 6-12 year-olds, even a portion who are nominally ineligible for education transfers because they have completed four grades (see

${ }^{13}$ Glewwe and Olinto (2004) report single-difference and difference-in-difference estimates. The single-difference estimates - which we emphasize here - are the unadjusted difference in the follow-up means of treatment and control groups. The difference-in-differences (DID) estimates further subtract the difference in the baseline means of treatment and control groups. Their DID estimates for enrollment are smaller, which the authors attribute to the structure of the baseline data collection. Logistical constraints mandated that CCT municipalities were surveyed at baseline from August to October 2000, while control municipalities were surveyed from November to December. The school year ends and agriculture work increases in November, introducing a mechanical positive baseline differences in school enrollment (and a negative difference in child labor). The follow-up data collection in 2002 was not similarly staggered across treatment and control groups.

${ }^{14}$ Glewwe and Olinto (2004) do not report the difference in proportions between G1/G2 and G3/G4, or its cluster-adjusted standard error. We calculated the difference using the sample sizes and the proportions for each of the four groups from the follow-up survey (see their Tables 1 and 9). Using the same data we then calculated a naïve standard error and, to account for clustering, multiplied it by $\sqrt{1+\rho(n-1)}$, the square root of the design effect; $\rho=0.058$ is the intra-class correlation in the 70 experimental municipalities — estimated with the 2001 census — and $n=100.1$ is the average follow-up sample size within each municipality. The same method is applied for other dependent variables. Full results are available from the authors. 
section 2.2). To draw a more accurate comparison with census estimates, we re-estimated the even-column regressions in panel B, using all 6-12 year-olds, and found slightly attenuated effects of 6.9 percentage points on enrollment and -2.6 percentage points on child work, with similar standard errors. In summary, the size and statistical significance of the full-sample enrollment results is quite consistent across the survey and census data. The effect on child labor is closer to zero (and statistically insignificant) in the survey data. However, the standard error of 1.7 and the $95 \%$ confidence interval are consistent with declines in child work as large as 3.8 percentage points.

\subsection{Heterogeneity}

Figure 3 presents visual evidence that the size of effects depends on the mean height-for-age z-score of municipalities $(H A Z)$, the variable used to define experimental blocks 1 to 5 . We estimated local linear regressions (bandwidth $=0.3$, rectangular kernel) of each dependent variable on $H A Z$. The dashed lines reports fitted values from regressions estimated in the pooled sample of eligible children in G1 and G2, while the solid lines refer to the sample of children in G3 and G4. Vertical dotted lines indicate values of $H A Z$ that define blocks 1 to 5 (while the right-most line, at -2.304 , indicates the cutoff for inclusion in the experimental sample). ${ }^{15}$ The figure shows a pattern of larger treatment-control differences at lower values of $H A Z$, particularly in the poorest blocks 1 and 2 .

In block 1, for example, the primary school enrollment rate in the control group is $55 \%$, well below the national mean of $75 \%$ among children who meet similar eligibility criteria (see Tables 1 and 3). Figure 3 shows that enrollments are roughly 20 percentage point higher in the treatment

\footnotetext{
${ }^{15}$ The quintiles of municipalities are defined by the z-scores $-2.7885,-2.6308,-2.4793$, and 2.363 .
} 
group - essentially at the national mean — suggesting that a modest cash transfer had a very large effect. A similar pattern is evident for child work outside the home in block 1. Fourteen percent of control-group children work outside the home, compared to a national mean of 5\%, while the treatment group rate is similar to the national mean.

Returning to Table 2, panel C reports regressions in which CCT is interacted with five block dummy variables. Focusing on even columns that include a full set of controls, the results confirm that enrollment effects are larger in poorer blocks (17.8 and 10.4 percentage points in blocks 1 and 2, respectively), and smaller and statistically insignificant in blocks 3 to 5 . One can reject the null hypothesis ( $p$-value $=0.07)$ that effects are equal across blocks. A similar pattern is observed for child work. In blocks 1 and 2, the rate of child work outside the home falls by 7.9 and 5 percentage points, respectively. We reject the null hypothesis that effects are equal across blocks ( $p$-value $=0.06)$. The rate of child work inside the home falls by 6.3 and 5.8 percentage points (although the null of coefficient equality cannot be rejected at conventional levels of statistical significance). The pattern of results is substantively similar in Panel D, where blocks 1-2 and 3-5 are analyzed as 2 groups rather than 5.

Overall, the results imply that a modest annual education transfer of US\$50 per child had very large effects in the poorest Honduran municipalities, both in increasing schooling and reducing child labor. In blocks 1 and 2, the point estimates imply 16-32\% increases in enrollment relative to the control group, $50-55 \%$ decreases in work outside the home, and 38$46 \%$ decreases in work inside the home. Significant effects are not observed in relatively lesspoor municipalities.

Table 4 further examines heterogeneity by child and household variables. In panels A to D, the variable $C C T$ is fully interacted with dummy variables indicating categories of a background 
variable. Regressions are estimated separately in samples from blocks 1-2 and blocks 3-5. In panel A, the magnitude of enrollment effects in poorer blocks is largest among younger children, while the reductions on work outside the home are largest among older children. In panel B, enrollment effects are very similar by gender, but boys drive the full-sample effect on work outside the home. Girls drive the full-sample effects on work inside the home. Notably, there is still little evidence of any effects by subgroups in blocks 3-5.

Panels C and D examine heterogeneity by two household attributes. According to program rules, no more than 3 education transfers are awarded to each household. We do not directly observe each child's participation, but effects on an eligible child should be attenuated if that child has a reduced likelihood of receiving a transfer within a larger household. Panel C suggests that is the case for enrollment. In blocks 1-2, for example, the effect is 12 percentage points for eligible children in household with 4 or more eligible children, versus 15 percentage points in households with 1-3 eligible children ( $p$-value $=0.02$ ). There is no strong evidence of a similar difference for child labor variables. Panel D assesses whether the effects on children eligible for the education transfers are partly attributable to health transfers received on behalf of younger children in the household (recalling that families were eligible to receive a maximum of 2 transfers for children under 3 or pregnant mothers). Overall, the magnitudes of coefficients and the corresponding $p$-values do not suggest that results among older children are driven by transfer income from younger children.

Finally, panel E assesses whether the findings on heterogeneity by block may conceal effects among poor children who reside in "richer" blocks (or the absence of effects among better-off children in blocks 1 and 2). The Honduran census form does not include measures of income or consumption. As an alternative, we estimated the probability of extreme poverty for eligible 
children in the census sample, using a 1999 household survey gathered just before randomization. ${ }^{16}$ Among eligible children, the mean probability is 0.88 , with $5^{\text {th }}$ and $95^{\text {th }}$ percentiles of 0.53 and 0.99. Given assumptions described in Tarozzi and Deaton (2009), this implies an estimated headcount ratio of $88 \%$ among all eligible children. In the control group, it declines from $93 \%$ in block 1 to $84 \%$ in block 5 (see Table 3 ). ${ }^{17}$ While monotonically declining, the headcount ratios emphasize the high incidence of extreme poverty even in block 5 . They also show that even small differences in block-level poverty are associated with large differences in the magnitude of treatment effects.

The estimates in panel $\mathrm{E}$ interact the continuously-measured probability with $C C T$. In blocks $1-2$, the implied enrollment effect is 2 percentage points for a child at the $5^{\text {th }}$ percentile, vs. 17 percentage points at the $95^{\text {th }}$ (recalling from Table 2 that the pooled effect in blocks 1-2 is 15 percentage points). Child work declines by 1 and 8 percentage points for a child at the $5^{\text {th }}$ and $95^{\text {th }}$ percentiles, respectively (with a pooled effect of 7 percentage points). In short, there is strong evidence that large effects are attenuated among the small group of children in blocks 1 and 2 who are less likely to be poor. ${ }^{18}$ This is not true within blocks 3-5. Although correctlysigned, the coefficients in this sample are smaller and statistically insignificant. Overall, the

\footnotetext{
${ }^{16}$ We used the 1999 sample of 6-12 year-olds who have not completed fourth grade, preparing independent variables identical to those in Table 1, with the exception of born in municipality, Lenca, other, auto, refrigerator, computer, television, and Mitch which are not included in the household survey. We then calculated an indicator of extreme poverty using household income per capita and an extreme poverty line of 6,462 Lempiras per person (IFPRI, 2000). We estimated a logit regression of poverty on the independent variables, using the specification described in the note to Table 2. Finally, we used the model estimates and census data to predict a probability of extreme poverty for each eligible child in the census.

${ }^{17}$ As in most poverty mapping exercises, the most problematic assumption is area homogeneity, or that the conditional distribution of poverty given the independent variables in the experimental municipalities is the same nationwide (Tarozzi and Deaton, 2009). For that reason, we regard the poverty estimates as illustrative.

${ }^{18}$ The same pattern of results holds when using wealth proxies from Table 1 such as a dirt floor.
} 
results suggests that effects are concentrated among the poorest households residing in the poorest municipalities. We hesitate to draw strong conclusions, however, since a violation of the area homogeneity assumption could lead to systematic errors in poverty predictions across municipalities (Tarozzi and Deaton, 2009).

\subsection{Effects on Ineligible Children and Adults}

Table 5 limits the sample to children ages 6-12 who are ineligible for education transfers by virtue of already having completed the fourth grade. Unsurprisingly, the sample contains no 6-8 year-olds. To assess whether spillover effects occur within families or through another mechanism, we identify ineligible children who reside in households: (1) with no children eligible for health or education transfers; (2) with at least 1 child eligible for an education transfer; and (3) with at least one child eligible for a health or education transfer.

For all dependent variables, the full-sample estimates in odd columns show no evidence of spillover effects on ineligible children. The coefficients are small and statistically insignificant. There is some evidence that enrollment increases (panel A) and work outside the home declines (panel B) among ineligible children in block 1. The magnitude of the enrollment effect is about one-third the size of the effect in the sample of eligible children, and comparable or somewhat smaller for child labor. The relative stability of point estimate across samples suggests that it is not driven by the presence other eligible children in the household. Beyond spillover effects, a plausible explanation is that program administrators subjectively loosened grade-related eligibility requirements for age-eligible children in the very poorest municipalities. Whatever the explanation, it is fair to conclude that evidence on spillovers is less compelling than evidence 
from the Progresa experiment, which offered relatively more generous transfers (Bobonis and Finan, 2009; Angelucci et al., 2010).

Table 6 reports estimates within samples of male and female adults (ages 21-65), again dividing samples by the presence or absence of eligible children in the household. In the full sample, the only marginally significant findings reveal an increase of less than one percentage point, among males, in the probability of working only in the home (it is apparently offset by a small decrease in work outside the home, although those coefficients are not significant). ${ }^{19}$ This result is stable across samples, even when there are no children in the household eligible for health or education transfers. When divided by block, it appears that the previous results for males are driven by slightly larger effects in blocks 4 and 5 . We examine the robustness of this finding in the next section, since local average treatment effects in the vicinity of the $H A Z$ cutoff used to select the experimental sample are informative about the magnitude of the average treatment effect in block 5 .

\subsection{Robustness}

The experimental sample included municipalities with the lowest values of $H A Z$. Define a dummy variable $E_{i j k}=1\left\{H A Z_{j k} \leq-2.304\right\}$, indicating individuals residing in 73 municipalities initially eligible for random assignment (among 298 nationally). Three municipalities were non-randomly excluded from random assignment because of distance and

\footnotetext{
${ }^{19}$ It is possible that the local hiring of PRAF personnel affected local labor supply. Between 1999 and 2001, the total expenditures on delivery of the CCTs - the activity most likely to involve locally-hired personnel — was approximately US $\$ 430,000$ in the 40 treated municipalities, an unknown portion of which constituted the local wage bill (see Tables 2 and 3 in Caldés et al., 2006). However, the average adult in the experimental sample had very low levels of formal schooling, and many employees were based in the PRAF office in Tegucigalpa. We cannot separately identify effects due to the CCTs or the local hiring of PRAF personnel.
} 
cost concerns. The random assignment further removed 30 municipalities in the experimental control group. Even so, individuals residing in municipalities with a $H A Z$ just below -2.304 should have sharply higher probabilities of residing in a municipality with PRAF-II transfers, implying a fuzzy regression discontinuity design (Lee and Lemieux, 2010).

This would be straightforward to implement but for a practical complication: $H A Z_{j k}$ is only observed for the 70 experimental municipalities. The 1997 height census is available in printed form for 298 municipalities, but the document records only three municipal variables: (1) the proportion of children in a municipality with z-scores less than $-3,(2)$ the proportion with zscores between -3 and -2 , and (3) the number of surveyed first-graders (Secretaría de Educación, 1997). To estimate $H A Z_{j k}$ using these data, we regress the right-censored $H A Z_{j k}$ on the two observed proportions and the interaction term, weighting by the number of surveyed firstgraders. ${ }^{20}$ We then calculated a predicted value, $\widehat{H A Z}$, for 298 municipalities. In the 70 experimental municipalities, $\operatorname{corr}(H A Z, \widehat{H A Z})=0.96$.

The discontinuity design identifies effects in the vicinity of the cutoff that bounds block 5 . Figure 4 allows a visual assessment of whether discontinuities are evident. In each panel, the lines are fitted values from local linear regressions estimated in the sample of eligible children (the $\mathrm{x}$-axis variable, $\widehat{H A Z}$, is re-centered such that 0 is the cutoff). The upper-left panel suggests that an eligible child's probability of residing in a treated municipality increases sharply at the cutoff by over 0.2 . The upper-right panel shows no evidence of a sharp increase in enrollment near the cutoff, while the bottom-left panel suggests a small increase in work outside the home. Both panels illustrate a reversal of the slope on either side of the cutoff, consistent with

${ }^{20} \mathrm{We}$ use an interval regression estimator (Wooldridge, 2010, p. 783). Unobserved values of $H A Z_{j k}$ were mostly right-censored at -2.304 . However, the three municipalities excluded for distance and cost considerations were known to fall within the interval of -2.3862 and -2.3678 , given the availability of the experimental municipalities' original rankings in the dataset. 
experimental findings reported in Figure 3. Finally, the lower-right panel confirms, as expected, that there is a positive relationship between $\widehat{H A Z}$ and mother's schooling, but it is apparently continuous in the vicinity of the cutoff; this provides evidence of the internal validity of the regression-discontinuity design. Collectively, the panels suggest that the experimental results from the "richest" block are robust to the use of an alternate control group.

Table 7 reports several regression specifications, including:

$$
C C T_{i j k}=\beta_{0}+\beta_{1} E_{i j k}+\beta_{2}\left(\widehat{H A Z}_{j k}+2.304\right)+\beta_{2} \times E_{i j k} \times\left(\widehat{H A Z}_{j k}+2.304\right)+\varepsilon_{i j k},
$$

where $\beta_{1}$ represents the increase in probability of treatment at the assignment cutoff, and the slope of $\widehat{H A Z}$ is allowed to vary on either side of the cutoff (the regression also includes the controls listed in the note to Table 2, except for block dummy variables). We also report results from specifications with quadratic and cubic polynomials of $\widehat{H A Z}$, not interacted with $E_{i j k}$. The sample includes all eligible children residing in municipalities with a $\widehat{H A Z}$ within 0.5 of the cutoff.

The specifications confirm that the probability of treatment increased by about 0.3 near the cutoff, although only the specification in column (1) is significant at 5\%. Panels B to D replace the dependent variable in equation (3) with each child outcome. The estimates are small and incorrectly-signed, although they are not precisely estimated. ${ }^{21}$ Finally, panel E confirms that there is no evidence of a discontinuity in mother's schooling near the cutoff (other results, not reported here, confirm the same for other child and household variables in Table 1).

We repeated the analyses for the adult labor supply outcomes, although they are not reported here. Among males, the negative effect on labor supply in block 5 was not replicated; in fact, the

${ }^{21}$ The magnitudes are similar if a smaller bandwidth $(0.3)$ is used. The probability of receiving CCTs increases by 0.25 to 0.38 in the vicinity of the cutoff, depending on the specification of the running variable $(n=192,475)$. The point estimates are -0.01 to -0.003 for enrollment, and 0.016 to 0.019 for child work. None of the coefficents are statistically significant at $10 \%$. 
small point estimates were of the opposite sign, small, and statistically significant at $5 \%$. Finally, we estimated the regression in the subsample of eligible children whose predicted probability of extreme poverty (see section 5.2) is greater than the sample median of 0.85 . This also produced no evidence of effects in block 5, with small and incorrectly-signed coefficients.

In summary, the regression-discontinuity estimates are broadly consistent with the small size of the experimental estimates in block 5, although they are imprecisely estimated. The exercise also provides an illustration of the frequent caveat accompanying discontinuity designs: that a local average treatment effect at a discontinuity may not replicate the average treatment effect among all treated subjects. Oosterbeek et al. (2008) report a similar finding in Ecuador, with positive and significant enrollment effects in a poor, experimental sample, and statistically insignificant effects in a less-poor sample using a discontinuity design. ${ }^{22}$

\section{Conclusions}

This paper analyzes the Honduran PRAF-II experiment using 2001 census data. PRAF-II awarded cash transfers, conditional on school enrollment, to children ages 6-12 who had not completed fourth grade. Cash transfers were available in 40 randomly-chosen municipalities in an experimental sample of 70 poor municipalities. The 70 municipalities (of 298 total) were chosen because their mean height-for-age z-score of first-graders fell below a cutoff value. In the full sample of children eligible for education transfers, we find that residing in a treated municipality increased school enrollment by 8 percentage points, decreased work outside the

\footnotetext{
${ }^{22}$ But, analyzing Progresa data, Buddelmeyer and Skoufias (2004) find inconsistent results. Using the fact that eligibility was determined by a proxy means test within localities, they estimated discontinuity effects local to these cutoffs. In an earlier round of data, these were zero or smaller than experimental estimates among the (poor) experimental sample. In a later round of follow-up data, the experimental and discontinuity effects were more comparable.
} 
home by 3 percentage points, and decreased work exclusively inside the home by 4 percentage points.

Caldés et al. (2006) report a total administrative program cost of US $\$ 2,881,200$ between 1999 and 2001, excluding the value of the cash transfers. ${ }^{23}$ There are 77,500 children eligible for education transfers in the treated municipalities, and 43,790 eligible for health transfers, implying that $64 \%$ of administrative costs are incurred in the distribution of education transfers. The cost per child—among those eligible for an education transfer-is about $\$ 24$ $(2,881,200 \times 0.64 \div 77,500)$. Following Evans and Ghosh (2008), we multiply this by 1.4 to adjust for the deadweight loss of taxation. We further estimate the deadweight loss of an education transfer of 800 Lempiras $(800 \div 15 \times 0.4)$, following Caldés et al. (2006) by assuming an exchange rate of 15 per dollar. The total cost per eligible child—including deadweight loss and excluding the actual cash transfers-is about $\$ 55$.

Given a full-sample effect on enrollment of 8 percentage points (or 12\%), the results imply a cost-effectiveness ratio of $\$ 4.58$ for a $1 \%$ (rather than percentage point) gain in enrollment. These are in the lower range of similarly-calculated cost-effectiveness ratios for interventions aimed at increasing enrollment (Evans and Ghosh, 2008). We also find substantial heterogeneity by the stratifying variable of mean municipal height-for-age, with full-sample effects accounted for by municipalities in the 2 poorest experimental blocks. In the combined sample of blocks 1 and 2, enrollment increased by 15 percentage points, or $25 \%$ of the control-group enrollment rate, implying an even lower cost of $\$ 2.20$ for $1 \%$ gain in enrollment.

The heterogeneous results point to the importance of adequate targeting in order to maximize the impact and cost-effectiveness of CCTs. Finally, we find little evidence of spillovers to

${ }^{23}$ The figure also excludes the costs of the impact evaluation, and the administrative costs involved in the delivery (or lack thereof) of the direct investments in schools and health centers. 
ineligible children and impacts on adult labor supply. The findings of small effects in blocks 3-5 were robust to use of a regression-discontinuity design implied by the rule used to select experimental municipalities.

\section{Acknowledgements}

We are grateful to Claudia Aguilar, Paul Glewwe, Luis Marcano, Renán Rápalo, and ESA Consultores for their generous assistance in obtaining data. Kristin Butcher, Dan Fetter, Adrienne Lucas, John Maluccio, Robin McKnight, Kartini Shastry, Gustavo Torrens, the editor, anonymous referees, and many seminar participants provided helpful comments. 


\section{References}

Adato, M., Hoddinott, J. (Eds.), 2011. Conditional Cash Transfers in Latin America. International Food Policy Research Institute, Washington, DC.

Alatas, V., Banerjee, A., Hanna, R., Olken, B., Tobias, J., 2012. Targeting the poor: evidence from a field experiment in Indonesia. American Economic Review. 102 (4), 1206-1240.

Alzúa, M.L., Cruces, G., Ripani, R. Forthcoming. Welfare programs and labor supply in developing countries: experimental evidence from Latin America. Journal of Population Economics.

Angelucci, M., de Giorgi, G., Rangel, M., Rasul, I., 2010. Family networks and school enrollment: evidence from a randomized social experiment. Journal of Public Economics. 94 (3-4), 197-221.

Banco Interamericano de Desarrollo (BID), 2004. Honduras: Programa Integral de Protección Social (HO-0222), Propuesta de Préstamo. Banco Interamericano de Desarrollo, Washington, DC.

Banerjee, A.V., Duflo, E., 2011. Poor Economics: A Radical Rethinking of the Way to Fight Global Poverty. PublicAffairs, New York.

Barrera-Osorio, F., Bertrand, M., Linden, L.L., Perez-Calle, F., 2011. Improving the design of conditional cash transfer programs: evidence from a randomized experiment in Colombia. American Economic Journal: Applied Economics. 3, 167-195.

Behrman, J.R., Parker, S.W., 2011. The impacts of conditional cash transfer programs on education, in: Adato, M., Hoddinott, J. (Eds.), Conditional Cash Transfers in Latin America. International Food Policy Research Institute, Washington, DC.

Behrman, J.R., Parker, S.W., Todd, P.E., 2009. Medium-term impacts of the Oportunidades conditional cash transfer program on rural youth in Mexico, in: Klasen, S., Nowak-Lehmann, F. (Eds.), Poverty, Inequality and Policy in Latin America. MIT Press, Cambridge, MA.

Behrman, J.R., Parker, S.W., Todd, P.E., 2011. Do conditional cash transfers for schooling generate lasting benefits? A five-year followup of PROGRESA/Oportunidades. Journal of Human Resources. 46 (1), 93-122.

Behrman, J.R., Sengupta, P., Todd, P., 2005. Progressing through PROGRESA: an impact assessment of a school subsidy experiment in rural Mexico. Economic Development and Cultural Change. 54 (1), 237-275.

Bobonis, G.J., Finan, F., 2009. Neighborhood peer effects in secondary school enrollment decisions. Review of Economics and Statistics. 91 (4), 695-716. 
Buddelmeyer, H., Skoufias, E., 2004. An evaluation of the performance of regression discontinuity design on PROGRESA. Policy Research Working Paper 3386. World Bank, Washington, DC.

Caldés, N., Coady, D., Maluccio, J.A., 2006. The cost of poverty alleviation transfer programs: a comparative analysis of three programs in Latin America. World Development. 34 (5), 818837.

Coady, D., Grosh, M., Hoddinott, J., 2004. Targeting outcomes redux. World Bank Research Observer. 19 (1): 61-85.

Deaton, A., 2010. Instruments, randomization, and learning about development. Journal of Economic Literature. 48, 424-455.

De Wachter, S., Galiani, S., 2006. Optimal income support targeting. International Tax and Public Finance. 13 (6), 661-684.

Edmonds, E.V., Schady, N., 2012. Poverty alleviation and child labor. American Economic Journal: Economic Policy. 4 (4), 100-125.

Evans, D.K., Ghosh, A., 2008. Prioritizing educational investments in children in the developing world. Working Paper WR-587. RAND, Santa Monica, CA.

Filmer, D., Schady, N., 2008. Getting girls into school: evidence from a scholarship program in Cambodia. Economic Development and Cultural Change. 56, 581-617.

Fiszbein, A., Schady, N., 2009. Conditional Cash Transfers: Reducing Present and Future Poverty. World Bank, Washington, DC.

Glewwe, P., Olinto, P., 2004. Evaluating the impact of conditional cash transfers on schooling: an experimental analysis of Honduras' PRAF program. Unpublished manuscript, University of Minnesota and IFPRI-FCND. Downloaded Nov. 26, 2012 from http://pdf.usaid.gov/pdf_docs/PNADT588.pdf.

International Food Policy Research Institute (IFPRI), 2000. Second Report: Implementation Proposal for the PRAF/IDB Project—Phase II. International Food Policy Research Institute, Washington, DC.

Lee, D.S., Lemieux, T., 2010. Regression discontinuity designs in economics. Journal of Economic Literature. 48 (2), 281-355.

Maluccio, J.A., Flores, R., 2005. Impact evaluation of a conditional cash transfer program: the Nicaraguan Red de Protección Social. Research Report 141. International Food Policy Research Institute, Washington, DC.

Maluccio, J.A., Murphy, A., Regalia, F., 2010. Does supply matter? Initial school conditions and the effectiveness of conditional cash transfers for grade progression in Nicaragua. Journal of Development Effectiveness. 2 (1), 87-116. 
Moore, C., 2008. Assessing Honduras' CCT Programme PRAF, Programa de Asignación Familiar: Expected and Unexpected Realities. Country Study No. 15. International Poverty Center.

Morris, S.S., Flores, R., Olinto, P., Medina, J.M., 2004. Monetary incentives in primary health care and effects on use and coverage of preventive health care interventions in rural Honduras: cluster randomized trial. Lancet. 364, 2030-37.

Oosterbeek, H., Ponce, J., Schady, N., 2008. The impact of cash transfers on school enrollment: evidence from Ecuador. Policy Research Working Paper 4645. World Bank, Washington, DC.

República de Honduras, 2002. XVI Censo de Población y V de Vivienda. Instituto Nacional de Estadística, República de Honduras, Tegucigalpa.

Schady, N., Araujo, M.C., 2008. Cash transfers, conditions, and school enrollment in Ecuador. Economía. 8 (2), 43-70.

Schultz, T. P., 2004. School subsidies for the poor: evaluating the Mexican PROGRESA poverty program. Journal of Development Economics. 74 (1), 199-250.

Secretaría de Educación, 1997. VII Censo Nacional de Talla, Informe 1997. Secretaría de Educación, Programa de Asignación Familiar, Tegucigalpa.

Skoufias, E., 2005. PROGRESA and its impacts on the welfare of rural households in Mexico. Research Report 139. International Food Policy Research Institute, Washington, DC.

Skoufias, E., Parker, S.W., 2001. Conditional cash transfers and their impact on child work and schooling: evidence from the PROGRESA program in Mexico. Economía. 2 (1), 45-86.

Stecklov, G., Winters, P., Todd, J., Regalia, F., 2007. Unintended effects of poverty programmes in less developed countries: experimental evidence from Latin America. Population Studies. $61(2), 125-140$.

Tarozzi, A., Deaton, A., 2009. Using census and survey data to estimate poverty and inequality in small areas. Review of Economics and Statistics. 91 (4), 773-792.

Wooldridge, J., 2010. Econometric Analysis of Cross Section and Panel Data. MIT Press, Cambridge, MA. 
Table 1: Descriptive statistics on children eligible for the education transfer

\begin{tabular}{|c|c|c|c|c|c|c|c|c|c|}
\hline & \multirow{2}{*}{\multicolumn{2}{|c|}{$\begin{array}{l}\text { All Honduran } \\
\text { municipalities }\end{array}$}} & \multicolumn{7}{|c|}{ Experimental municipalities } \\
\hline & & & \multicolumn{2}{|c|}{ All } & \multirow{2}{*}{$\begin{array}{c}\text { G1 } \\
\text { Mean }\end{array}$} & \multirow{2}{*}{$\begin{array}{c}\text { G2 } \\
\text { Mean } \\
\end{array}$} & \multirow{2}{*}{$\begin{array}{c}\text { G3 } \\
\text { Mean } \\
\end{array}$} & \multirow{2}{*}{$\begin{array}{c}\text { G4 } \\
\text { Mean } \\
\end{array}$} & \multirow[b]{2}{*}{ p-value } \\
\hline & Mean & $\mathrm{N}$ & Mean & $\mathrm{N}$ & & & & & \\
\hline \multicolumn{10}{|l|}{ Dependent variables } \\
\hline$\overline{\text { Enrolled in school }}$ & 0.753 & 950,683 & 0.701 & 120,411 & 0.739 & 0.723 & 0.636 & 0.650 & 0.018 \\
\hline Works outside home & 0.047 & 775,673 & 0.076 & 98,783 & 0.075 & 0.054 & 0.092 & 0.099 & 0.026 \\
\hline Works only in home & 0.100 & 775,673 & 0.110 & 98,783 & 0.101 & 0.089 & 0.141 & 0.134 & 0.035 \\
\hline \multicolumn{10}{|l|}{ Independent variables } \\
\hline Age & $\begin{array}{l}8.381 \\
(1.80)\end{array}$ & 950,683 & $\begin{array}{l}8.498 \\
(1.87)\end{array}$ & 120,411 & 8.449 & 8.505 & 8.550 & 8.528 & 0.189 \\
\hline Female & 0.481 & 950,683 & 0.483 & 120,411 & 0.484 & 0.483 & 0.483 & 0.483 & 0.918 \\
\hline Born in municipality & 0.871 & 950,683 & 0.924 & 120,411 & 0.934 & 0.905 & 0.929 & 0.933 & 0.581 \\
\hline Lenca & 0.053 & 950,683 & 0.319 & 120,411 & 0.391 & 0.266 & 0.336 & 0.286 & 0.317 \\
\hline Other & 0.029 & 950,683 & 0.035 & 120,411 & 0.005 & 0.049 & 0.063 & 0.041 & 0.295 \\
\hline Father is literate & 0.707 & 765,958 & 0.615 & 102,615 & 0.639 & 0.607 & 0.570 & 0.615 & 0.523 \\
\hline Mother is literate & 0.699 & 878,677 & 0.548 & 111,418 & 0.564 & 0.551 & 0.530 & 0.529 & 0.445 \\
\hline Father's schooling & $\begin{array}{l}3.653 \\
(3.97)\end{array}$ & 765,958 & $\begin{array}{l}2.321 \\
(2.72)\end{array}$ & 102,615 & 2.532 & 2.301 & 2.090 & 2.182 & 0.364 \\
\hline Mother's schooling & $\begin{array}{l}3.640 \\
(3.78)\end{array}$ & 878,677 & $\begin{array}{l}2.112 \\
(2.66)\end{array}$ & 111,418 & 2.261 & 2.153 & 1.973 & 1.917 & 0.232 \\
\hline Dirt floor & 0.434 & 936,249 & 0.719 & 118,697 & 0.726 & 0.724 & 0.728 & 0.698 & 0.893 \\
\hline Piped water & 0.680 & 936,249 & 0.643 & 118,697 & 0.642 & 0.645 & 0.652 & 0.636 & 0.974 \\
\hline Electricity & 0.475 & 936,249 & 0.144 & 118,697 & 0.146 & 0.156 & 0.096 & 0.151 & 0.848 \\
\hline Rooms in dwelling & $\begin{array}{l}1.682 \\
(0.90)\end{array}$ & 948,056 & $\begin{array}{l}1.405 \\
(0.72)\end{array}$ & 120,321 & 1.435 & 1.416 & 1.402 & 1.352 & 0.101 \\
\hline Sewer/septic & 0.413 & 948,056 & 0.305 & 120,321 & 0.346 & 0.297 & 0.287 & 0.269 & 0.312 \\
\hline Auto & 0.090 & 948,056 & 0.038 & 120,321 & 0.040 & 0.034 & 0.050 & 0.035 & 0.162 \\
\hline Refrigerator & 0.253 & 948,056 & 0.051 & 120,321 & 0.058 & 0.051 & 0.031 & 0.053 & 0.815 \\
\hline Computer & 0.018 & 948,056 & 0.002 & 120,321 & 0.003 & 0.002 & 0.000 & 0.002 & 0.177 \\
\hline Television & 0.373 & 948,056 & 0.076 & 120,321 & 0.090 & 0.072 & 0.047 & 0.078 & 0.781 \\
\hline Mitch & 0.035 & 948,056 & 0.015 & 120,321 & 0.020 & 0.014 & 0.008 & 0.014 & 0.205 \\
\hline Household members & $\begin{array}{l}7.080 \\
(3.75)\end{array}$ & 950,683 & $\begin{array}{l}7.404 \\
(2.41)\end{array}$ & 120,411 & 7.516 & 7.434 & 7.354 & 7.238 & 0.153 \\
\hline Household members, 0-17 & $\begin{array}{l}4.427 \\
(3.16)\end{array}$ & 950,683 & $\begin{array}{l}4.785 \\
(1.92)\end{array}$ & 120,411 & 4.852 & 4.820 & 4.770 & 4.655 & 0.261 \\
\hline Maximum $\mathrm{N}$ of children & 950,683 & & 120,411 & & 38,435 & 39,065 & 14,154 & 28,757 & \\
\hline $\mathrm{N}$ of municipalities & 298 & & 70 & & 20 & 20 & 10 & 20 & \\
\hline
\end{tabular}

Source: 2001 Honduran Census and authors' calculations.

Notes: All samples include children ages 6-12 who have not completed fourth grade. Standard deviations are in parentheses for continuous variables. The $p$-value in the final column is obtained by regressing each variable on three treatment group dummy variables and four of five block dummy variables — clustering standard errors by municipality — and testing the null hypothesis that coefficients on treatment group variables are jointly zero. 
Table 2: Effects on children eligible for the the education transfer

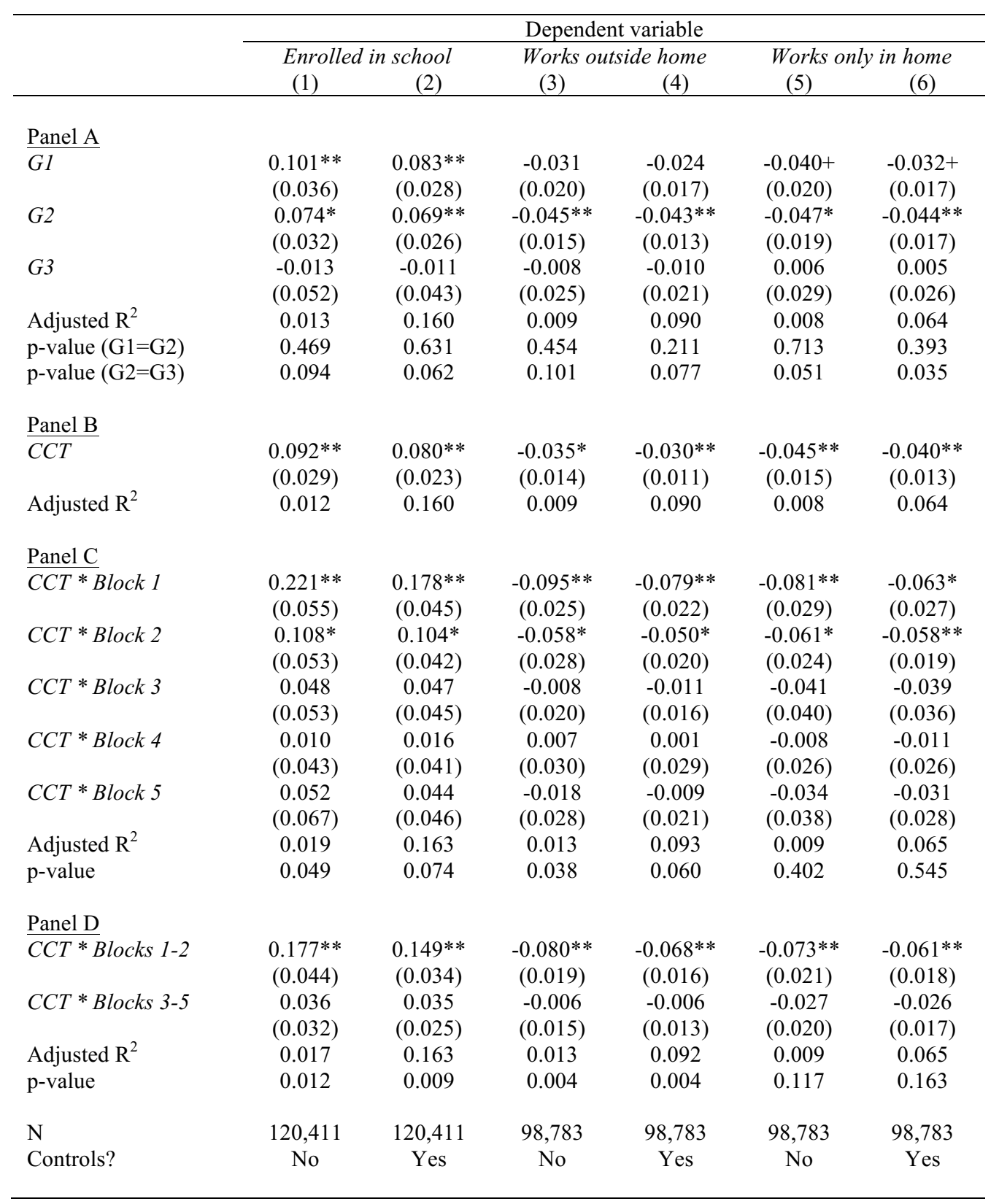

Notes: ** indicates statistical significance at $1 \%, *$ at $5 \%$, and + at $10 \%$. Robust standard errors are in parentheses, adjusted for municipal-level clustering. The sample includes children ages 6-12 who have not completed fourth grade. Each regression includes block dummy variables. Additional controls include (1) the independent variables in Table 1 (including age-specific dummy variables and quadratic polynomials for other continuous variables), (2) dummy variables indicating the number of children eligible for the education transfer in a household, (3) dummy variables indicating the number of children eligible for the health transfer, and (4) dummy variables indicating missing values of the independent variables. P-values refer to the null hypothesis that reported coefficients are equal. 
Table 3: Means in the combined control group of G3 and G4

\begin{tabular}{|c|c|c|c|c|c|c|}
\hline & $\begin{array}{c}\text { Full } \\
\text { sample }\end{array}$ & Block 1 & Block 2 & Block 3 & Block 4 & Block 5 \\
\hline \multicolumn{7}{|c|}{ Children eligible for education transfer } \\
\hline Enrolled in school & 0.646 & 0.555 & 0.662 & 0.702 & 0.654 & 0.682 \\
\hline Works outside home & 0.097 & 0.143 & 0.101 & 0.054 & 0.095 & 0.077 \\
\hline Works only in home & 0.136 & 0.168 & 0.125 & 0.113 & 0.137 & 0.129 \\
\hline$\widehat{\text { Poor }}$ & 0.887 & 0.925 & 0.900 & 0.893 & 0.869 & 0.841 \\
\hline \multicolumn{7}{|c|}{ Boys eligible for education transfer } \\
\hline Enrolled in school & 0.636 & 0.548 & 0.665 & 0.687 & 0.641 & 0.667 \\
\hline Works outside home & 0.153 & 0.227 & 0.152 & 0.094 & 0.144 & 0.130 \\
\hline Works only in home & 0.078 & 0.094 & 0.077 & 0.071 & 0.075 & 0.070 \\
\hline \multicolumn{7}{|c|}{ Girls eligible for education transfer } \\
\hline Enrolled in school & 0.655 & 0.563 & 0.660 & 0.717 & 0.667 & 0.699 \\
\hline Works outside home & 0.037 & 0.055 & 0.050 & 0.012 & 0.042 & 0.019 \\
\hline Works only in home & 0.198 & 0.245 & 0.173 & 0.157 & 0.204 & 0.194 \\
\hline \multicolumn{7}{|c|}{ Males between 21 and 65} \\
\hline Works outside home & 0.930 & 0.955 & 0.932 & 0.908 & 0.932 & 0.921 \\
\hline Works only in home & 0.020 & 0.023 & 0.018 & 0.024 & 0.013 & 0.023 \\
\hline \multicolumn{7}{|c|}{ Females between 21 and 65} \\
\hline Works outside home & 0.111 & 0.097 & 0.138 & 0.093 & 0.112 & 0.117 \\
\hline Works only in home & 0.860 & 0.873 & 0.834 & 0.878 & 0.857 & 0.852 \\
\hline
\end{tabular}

Note: Eligible children include children ages 6-12 who have not completed fourth grade. See text for definition of $\widehat{\text { Poor. }}$. 
Table 4: Heterogeneity in effects on children eligible for the education transfer

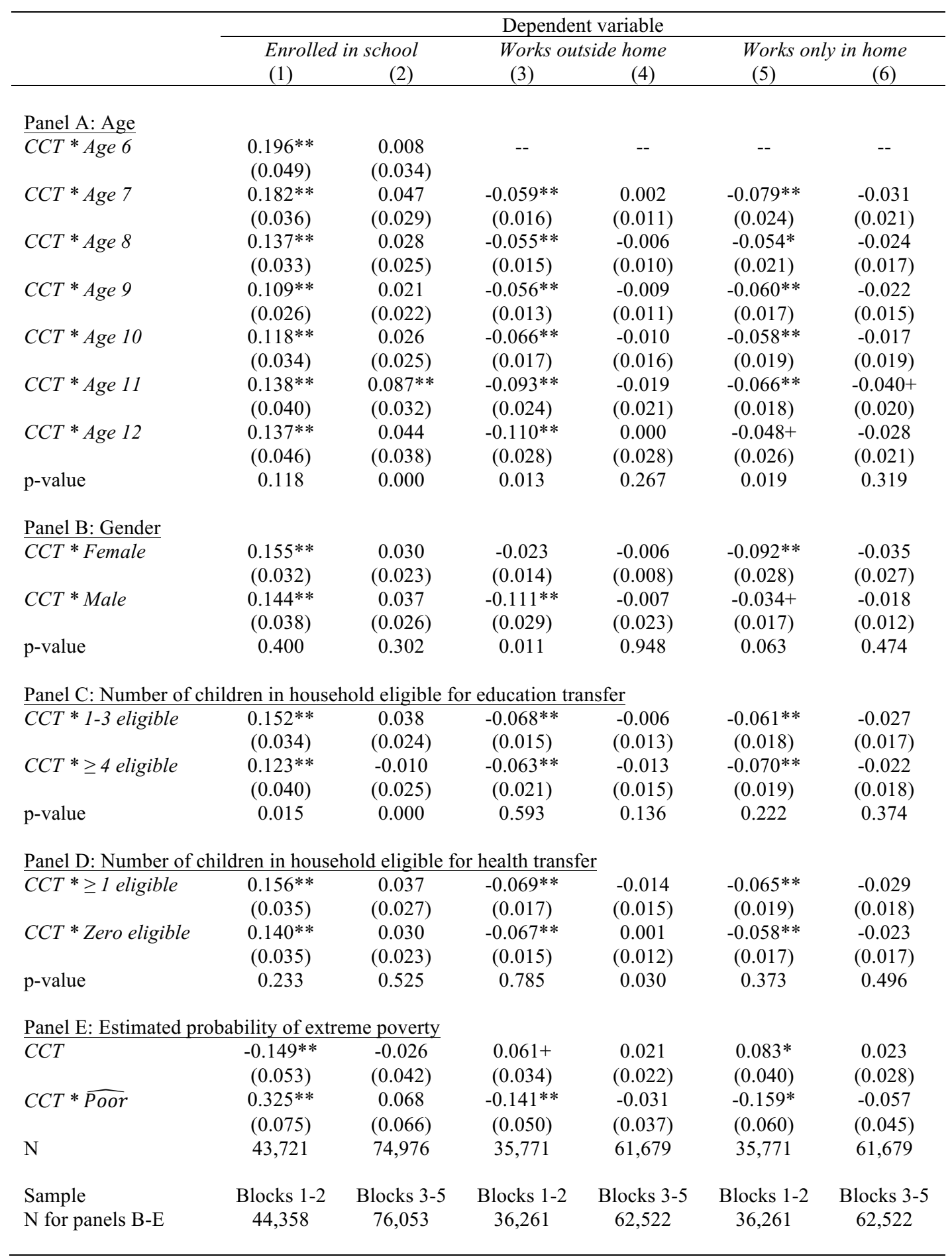

Notes: ** indicates statistical significance at $1 \%, *$ at $5 \%$, and + at $10 \%$. Robust standard errors are in parentheses, adjusted for municipal-level clustering. The samples includes children ages 6-12 who have not completed fourth grade. All regressions include the full set of controls described in the note to Table 2; regressions in panel E also control for $\widehat{\text { Poor }}$. P-values refer to the null hypothesis that reported coefficients are equal. 
Table 5: Effects on children ineligible for the education transfer

\begin{tabular}{|c|c|c|c|c|c|c|}
\hline \multirow{3}{*}{ Dependent variable } & \multicolumn{6}{|c|}{ Sample } \\
\hline & \multicolumn{2}{|c|}{$\begin{array}{l}\text { No eligible child in } \\
\text { household }\end{array}$} & \multicolumn{2}{|c|}{$\begin{array}{l}\geq 1 \text { eligible for education } \\
\text { transfer in household }\end{array}$} & \multicolumn{2}{|c|}{$\begin{array}{l}\geq 1 \text { eligible for education or } \\
\text { health transfer in } \mathrm{HH}\end{array}$} \\
\hline & $(1)$ & $(2)$ & $(3)$ & $(4)$ & $(5)$ & $(6)$ \\
\hline \multicolumn{7}{|c|}{ Panel A: Enrolled in school } \\
\hline$\overline{C C T}$ & $\begin{array}{l}-0.001 \\
(0.015)\end{array}$ & & $\begin{array}{c}0.008 \\
(0.011)\end{array}$ & & $\begin{array}{c}0.007 \\
(0.011)\end{array}$ & \\
\hline CCT * Block 1 & & $\begin{array}{c}0.057 \\
(0.039)\end{array}$ & & $\begin{array}{l}0.067 * * \\
(0.019)\end{array}$ & & $\begin{array}{l}0.067 * * \\
(0.019)\end{array}$ \\
\hline CCT * Block 2 & & $\begin{array}{l}-0.005 \\
(0.041)\end{array}$ & & $\begin{array}{l}-0.001 \\
(0.019)\end{array}$ & & $\begin{array}{l}-0.008 \\
(0.019)\end{array}$ \\
\hline CCT * Block 3 & & $\begin{array}{c}0.005 \\
(0.028)\end{array}$ & & $\begin{array}{l}-0.018 \\
(0.017)\end{array}$ & & $\begin{array}{l}-0.020 \\
(0.018)\end{array}$ \\
\hline CCT * Block 4 & & $\begin{array}{c}0.010 \\
(0.021)\end{array}$ & & $\begin{array}{l}-0.008 \\
(0.023)\end{array}$ & & $\begin{array}{l}-0.007 \\
(0.022)\end{array}$ \\
\hline CCT $*$ Block 5 & & $\begin{array}{l}-0.048+ \\
(0.026)\end{array}$ & & $\begin{array}{l}-0.005 \\
(0.019)\end{array}$ & & $\begin{array}{l}-0.001 \\
(0.020)\end{array}$ \\
\hline p-value & & 0.220 & & 0.017 & & 0.013 \\
\hline \multicolumn{7}{|c|}{ Panel B: Works outside home } \\
\hline$\overline{C C T}$ & $\begin{array}{l}-0.007 \\
(0.008)\end{array}$ & & $\begin{array}{l}-0.005 \\
(0.008)\end{array}$ & & $\begin{array}{l}-0.004 \\
(0.008)\end{array}$ & \\
\hline CCT $*$ Block 1 & & $\begin{array}{l}-0.050^{*} \\
(0.022)\end{array}$ & & $\begin{array}{l}-0.035+ \\
(0.019)\end{array}$ & & $\begin{array}{l}-0.034+ \\
(0.018)\end{array}$ \\
\hline CCT * Block 2 & & $\begin{array}{c}0.002 \\
(0.019)\end{array}$ & & $\begin{array}{l}-0.005 \\
(0.008)\end{array}$ & & $\begin{array}{l}-0.002 \\
(0.008)\end{array}$ \\
\hline CCT * Block 3 & & $\begin{array}{c}0.002 \\
(0.011)\end{array}$ & & $\begin{array}{l}-0.001 \\
(0.008)\end{array}$ & & $\begin{array}{l}-0.001 \\
(0.009)\end{array}$ \\
\hline CCT $*$ Block 4 & & $\begin{array}{l}-0.007 \\
(0.022)\end{array}$ & & $\begin{array}{c}0.011 \\
(0.021)\end{array}$ & & $\begin{array}{c}0.012 \\
(0.020)\end{array}$ \\
\hline CCT * Block 5 & & $\begin{array}{c}0.008 \\
(0.008)\end{array}$ & & $\begin{array}{c}0.004 \\
(0.017)\end{array}$ & & $\begin{array}{c}0.004 \\
(0.016)\end{array}$ \\
\hline p-value & & 0.175 & & 0.428 & & 0.420 \\
\hline \multicolumn{7}{|c|}{ Panel C: Works only in home } \\
\hline$C C T$ & $\begin{array}{c}0.005 \\
(0.012)\end{array}$ & & $\begin{array}{l}-0.001 \\
(0.008)\end{array}$ & & $\begin{array}{l}-0.000 \\
(0.008)\end{array}$ & \\
\hline CCT * Block 1 & & $\begin{array}{l}-0.008 \\
(0.031)\end{array}$ & & $\begin{array}{l}-0.020 \\
(0.019)\end{array}$ & & $\begin{array}{l}-0.017 \\
(0.019)\end{array}$ \\
\hline CCT * Block 2 & & $\begin{array}{l}-0.009 \\
(0.028)\end{array}$ & & $\begin{array}{c}0.013 \\
(0.017)\end{array}$ & & $\begin{array}{c}0.011 \\
(0.015)\end{array}$ \\
\hline CCT * Block 3 & & $\begin{array}{l}-0.015 \\
(0.036)\end{array}$ & & $\begin{array}{c}0.005 \\
(0.014)\end{array}$ & & $\begin{array}{c}0.007 \\
(0.014)\end{array}$ \\
\hline CCT * Block 4 & & $\begin{array}{c}0.008 \\
(0.011)\end{array}$ & & $\begin{array}{c}0.007 \\
(0.021)\end{array}$ & & $\begin{array}{c}0.007 \\
(0.021)\end{array}$ \\
\hline CCT * Block 5 & & $\begin{array}{l}0.033+ \\
(0.018)\end{array}$ & & $\begin{array}{c}-0.004 \\
(0.015)\end{array}$ & & $\begin{array}{l}-0.006 \\
(0.016)\end{array}$ \\
\hline p-value & & 0.546 & & 0.715 & & 0.762 \\
\hline $\mathrm{N}$ & 4,214 & 4,214 & 16,586 & 16,586 & 17,941 & 17,941 \\
\hline
\end{tabular}

Notes: $* * *$ indicates statistical significance at $1 \%, * *$ at $5 \%$, and + at $10 \%$. Robust standard errors are in parentheses, adjusted for municipal-level clustering. The sample includes children ages 6-12 who have completed fourth grade. All regressions include the full set of controls described in the note to Table 2. P-values refer to the null hypothesis that reported coefficients are equal. 
Table 6: Effects on adult labor supply

\begin{tabular}{|c|c|c|c|c|c|c|c|c|c|c|c|c|}
\hline \multirow{4}{*}{$\begin{array}{l}\text { Dependent } \\
\text { variable }\end{array}$} & \multicolumn{12}{|c|}{ Sample } \\
\hline & \multicolumn{6}{|c|}{ Males } & \multicolumn{6}{|c|}{ Females } \\
\hline & \multicolumn{2}{|c|}{$\begin{array}{c}\text { No eligible child in } \\
\text { household }\end{array}$} & \multicolumn{2}{|c|}{$\begin{array}{l}\geq 1 \text { eligible for educ. } \\
\text { transfer in household }\end{array}$} & \multicolumn{2}{|c|}{$\begin{array}{c}\geq 1 \text { eligible for educ. or } \\
\text { health transfer in } \mathrm{HH}\end{array}$} & \multicolumn{2}{|c|}{$\begin{array}{c}\text { No eligible child in } \\
\text { household }\end{array}$} & \multicolumn{2}{|c|}{$\begin{array}{l}\geq 1 \text { eligible for educ. } \\
\text { transfer in household }\end{array}$} & \multicolumn{2}{|c|}{$\begin{array}{l}\geq 1 \text { eligible for educ. } \mathrm{o} \\
\text { health transfer in } \mathrm{HH}\end{array}$} \\
\hline & $(1)$ & $(2)$ & (3) & $(4)$ & $(5)$ & $(6)$ & $(7)$ & $(8)$ & $(9)$ & $(10)$ & $(11)$ & $(12)$ \\
\hline \multicolumn{13}{|c|}{ Panel A: Works outside home } \\
\hline$C C T$ & $\begin{array}{l}-0.013 \\
(0.009)\end{array}$ & & $\begin{array}{l}-0.014 \\
(0.009)\end{array}$ & & $\begin{array}{l}-0.013 \\
(0.008)\end{array}$ & & $\begin{array}{c}0.012 \\
(0.018)\end{array}$ & & $\begin{array}{c}0.008 \\
(0.018)\end{array}$ & & $\begin{array}{c}0.008 \\
(0.018)\end{array}$ & \\
\hline CCT * Block 1 & & $\begin{array}{l}-0.016 \\
(0.013)\end{array}$ & & $\begin{array}{l}-0.018 \\
(0.012)\end{array}$ & & $\begin{array}{l}-0.017 \\
(0.012)\end{array}$ & & $\begin{array}{l}0.046+ \\
(0.027)\end{array}$ & & $\begin{array}{c}0.033 \\
(0.030)\end{array}$ & & $\begin{array}{c}0.032 \\
(0.028)\end{array}$ \\
\hline$C C T *$ Block 2 & & $\begin{array}{c}0.026 \\
(0.027)\end{array}$ & & $\begin{array}{c}0.010 \\
(0.018)\end{array}$ & & $\begin{array}{c}0.007 \\
(0.016)\end{array}$ & & $\begin{array}{c}0.012 \\
(0.090)\end{array}$ & & $\begin{array}{l}0.028 \\
(0.084)\end{array}$ & & $\begin{array}{c}0.026 \\
(0.085)\end{array}$ \\
\hline$C C T$ * Block 3 & & $\begin{array}{c}0.015 \\
(0.014)\end{array}$ & & $\begin{array}{c}0.023 \\
(0.019)\end{array}$ & & $\begin{array}{c}0.024 \\
(0.018)\end{array}$ & & $\begin{array}{l}-0.020 \\
(0.018)\end{array}$ & & $\begin{array}{l}-0.017 \\
(0.018)\end{array}$ & & $\begin{array}{l}-0.017 \\
(0.018)\end{array}$ \\
\hline CCT * Block 4 & & $\begin{array}{c}-0.039 * * \\
(0.014)\end{array}$ & & $\begin{array}{r}-0.024+ \\
(0.013)\end{array}$ & & $\begin{array}{r}-0.022+ \\
(0.012)\end{array}$ & & $\begin{array}{c}0.000 \\
(0.023)\end{array}$ & & $\begin{array}{l}-0.012 \\
(0.026)\end{array}$ & & $\begin{array}{l}-0.012 \\
(0.024)\end{array}$ \\
\hline$C C T *$ Block 5 & & $\begin{array}{l}-0.032 \\
(0.024)\end{array}$ & & $\begin{array}{l}-0.050^{*} \\
(0.023)\end{array}$ & & $\begin{array}{l}-0.050^{*} \\
(0.022)\end{array}$ & & $\begin{array}{c}0.018 \\
(0.035)\end{array}$ & & $\begin{array}{c}0.011 \\
(0.027)\end{array}$ & & $\begin{array}{c}0.013 \\
(0.025)\end{array}$ \\
\hline $\mathrm{p}$-value & & 0.035 & & 0.068 & & 0.059 & & 0.380 & & 0.596 & & 0.580 \\
\hline \multicolumn{13}{|c|}{ Panel B: Works only in home } \\
\hline$\overline{C C T}$ & $\begin{array}{l}0.007+ \\
(0.004)\end{array}$ & & $\begin{array}{l}0.008+ \\
(0.004)\end{array}$ & & $\begin{array}{l}0.008+ \\
(0.004)\end{array}$ & & $\begin{array}{l}-0.013 \\
(0.018)\end{array}$ & & $\begin{array}{l}-0.009 \\
(0.018)\end{array}$ & & $\begin{array}{l}-0.009 \\
(0.018)\end{array}$ & \\
\hline CCT $*$ Block 1 & & $\begin{array}{l}-0.004 \\
(0.008)\end{array}$ & & $\begin{array}{c}0.002 \\
(0.011)\end{array}$ & & $\begin{array}{c}0.002 \\
(0.011)\end{array}$ & & $\begin{array}{l}-0.034 \\
(0.025)\end{array}$ & & $\begin{array}{l}-0.035 \\
(0.034)\end{array}$ & & $\begin{array}{l}-0.032 \\
(0.031)\end{array}$ \\
\hline$C C T *$ Block 2 & & $\begin{array}{c}0.000 \\
(0.007)\end{array}$ & & $\begin{array}{l}-0.004 \\
(0.006)\end{array}$ & & $\begin{array}{l}-0.004 \\
(0.005)\end{array}$ & & $\begin{array}{l}-0.015 \\
(0.085)\end{array}$ & & $\begin{array}{l}-0.021 \\
(0.082)\end{array}$ & & $\begin{array}{l}-0.018 \\
(0.084)\end{array}$ \\
\hline CCT * Block 3 & & $\begin{array}{c}0.004 \\
(0.011)\end{array}$ & & $\begin{array}{c}0.006 \\
(0.013)\end{array}$ & & $\begin{array}{c}0.007 \\
(0.012)\end{array}$ & & $\begin{array}{c}0.028 \\
(0.018)\end{array}$ & & $\begin{array}{c}0.014 \\
(0.019)\end{array}$ & & $\begin{array}{c}0.012 \\
(0.019)\end{array}$ \\
\hline$C C T$ * Block 4 & & $\begin{array}{c}0.017 * * \\
(0.005)\end{array}$ & & $\begin{array}{c}0.016^{* *} \\
(0.004)\end{array}$ & & $\begin{array}{c}0.015 * * \\
(0.003)\end{array}$ & & $\begin{array}{l}-0.019 \\
(0.026)\end{array}$ & & $\begin{array}{c}0.007 \\
(0.027)\end{array}$ & & $\begin{array}{c}0.007 \\
(0.024)\end{array}$ \\
\hline$C C T *$ Block 5 & & $\begin{array}{l}0.015+ \\
(0.008)\end{array}$ & & $\begin{array}{l}0.016^{*} \\
(0.006)\end{array}$ & & $\begin{array}{c}0.016^{* *} \\
(0.006)\end{array}$ & & $\begin{array}{l}-0.022 \\
(0.035)\end{array}$ & & $\begin{array}{l}-0.010 \\
(0.027)\end{array}$ & & $\begin{array}{l}-0.013 \\
(0.025)\end{array}$ \\
\hline $\mathrm{p}$-value & & 0.098 & & 0.063 & & 0.024 & & 0.293 & & 0.743 & & 0.756 \\
\hline $\mathrm{N}$ & 29,671 & 29,671 & 68,754 & 68,754 & 90,291 & 90,291 & 25,992 & 25,992 & 75,182 & 75,182 & 94,254 & 94,254 \\
\hline
\end{tabular}

Notes: $* * *$ indicates statistical significance at $1 \%, * *$ at $5 \%$, and + at $10 \%$. Robust standard errors are in parentheses, adjusted for municipal-level clustering. The sample includes adults between the ages of 21 and 65 . All regressions include the full set of controls described in the note to Table 2 . P-values refer to the null hypothesis that reported coefficients are equal. 
Table 7: Regression discontinuity effects on children eligible for the education transfer

\begin{tabular}{|c|c|c|c|}
\hline Dependent variable & $(1)$ & (2) & (3) \\
\hline \multicolumn{4}{|l|}{ Panel A: $C C T$} \\
\hline $\bar{E}$ & $\begin{array}{c}0.299 * \\
(0.149)\end{array}$ & $\begin{array}{c}0.287+ \\
(0.151)\end{array}$ & $\begin{array}{c}0.299 \\
(0.193)\end{array}$ \\
\hline \multicolumn{4}{|c|}{ Panel B: Enrolled in school } \\
\hline$E$ & $\begin{array}{l}-0.016 \\
(0.028)\end{array}$ & $\begin{array}{l}-0.019 \\
(0.029)\end{array}$ & $\begin{array}{l}-0.005 \\
(0.037)\end{array}$ \\
\hline \multicolumn{4}{|c|}{ Panel C: Works outside home } \\
\hline$E$ & $\begin{array}{c}0.017 \\
(0.015)\end{array}$ & $\begin{array}{c}0.019 \\
(0.015)\end{array}$ & $\begin{array}{c}0.019 \\
(0.018)\end{array}$ \\
\hline \multicolumn{4}{|c|}{ Panel D: Works only in home } \\
\hline$E$ & $\begin{array}{c}0.008 \\
(0.016)\end{array}$ & $\begin{array}{c}0.009 \\
(0.016)\end{array}$ & $\begin{array}{c}0.008 \\
(0.022)\end{array}$ \\
\hline \multicolumn{4}{|c|}{ Panel E: Mother's schooling } \\
\hline$E$ & $\begin{array}{l}-0.053 \\
(0.234)\end{array}$ & $\begin{array}{c}-0.080 \\
(0.226)\end{array}$ & $\begin{array}{c}0.155 \\
(0.337)\end{array}$ \\
\hline Specification of $\widehat{H A Z}$ & $\begin{array}{l}\text { Linear (interacted } \\
\text { with } E \text { ) }\end{array}$ & Quadratic & Cubic \\
\hline Bandwidth & 0.5 & 0.5 & 0.5 \\
\hline
\end{tabular}

Notes: $* * *$ indicates statistical significance at $1 \%, * *$ at $5 \%$, and + at $10 \%$. Robust standard errors are in parentheses, adjusted for municipal-level clustering. The sample includes children ages 6-12 who have not completed fourth grade, residing in municipaities with $\widehat{H A Z}$ between -0.5 and 0.5 . The sample size in Panels A-B is 341,373 . The sample sizes in panels C-D is 280,762 . The sample size in panel E is 316,598 . In addition to the specified function of $\widehat{H A Z}$, the regressions in panels A-D include the full set of controls described in the note to Table 2. 
Figure 1: Timeline of PRAF-II and data collection

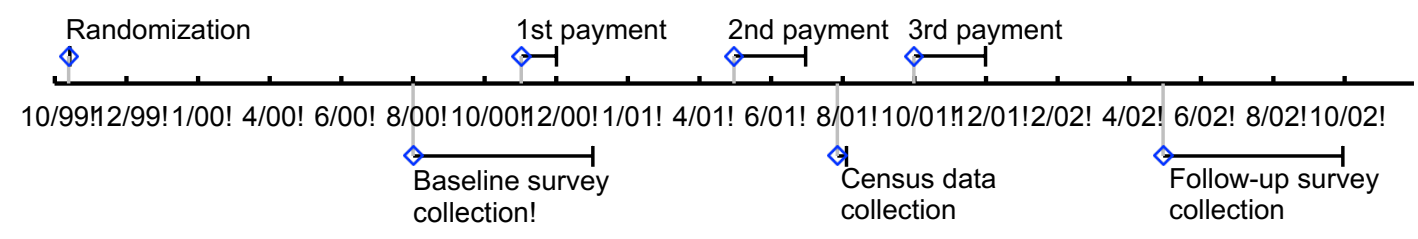

Source: IFPRI (2000) reports the date of randomization (October 13, 1999). Morris et al. (2004) report the dates of payments, including a fourth payment not shown on the timeline that "partly coincided with the post-intervention survey" (p. 2031). Glewwe and Olinto (2004) report dates of baseline and follow-up survey collection in the official evaluation; a small proportion of follow-up data collection occurred after September 2002. República de Honduras (2002) reports the census dates. 
Figure 2: Treated and untreated municipalities

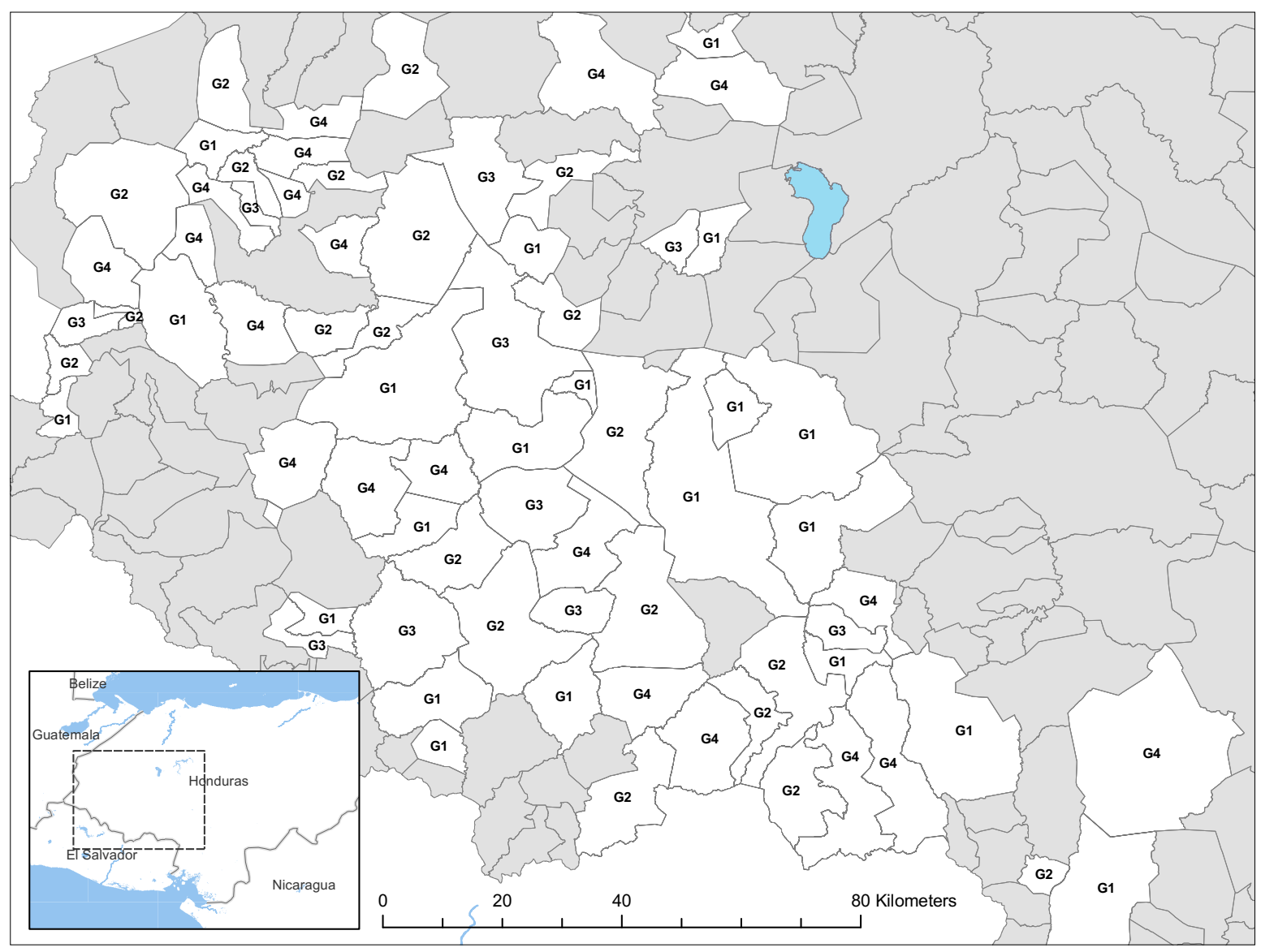

Notes: Unshaded municipalities were randomly assigned to receive cash transfers $(\mathrm{G} 1)$, to receive transfers and direct investments $(\mathrm{G} 2)$, to receive direct investments (G3), or to receive no treatment (G4). See text for details. 
Figure 3: Experimental treatment effects by block
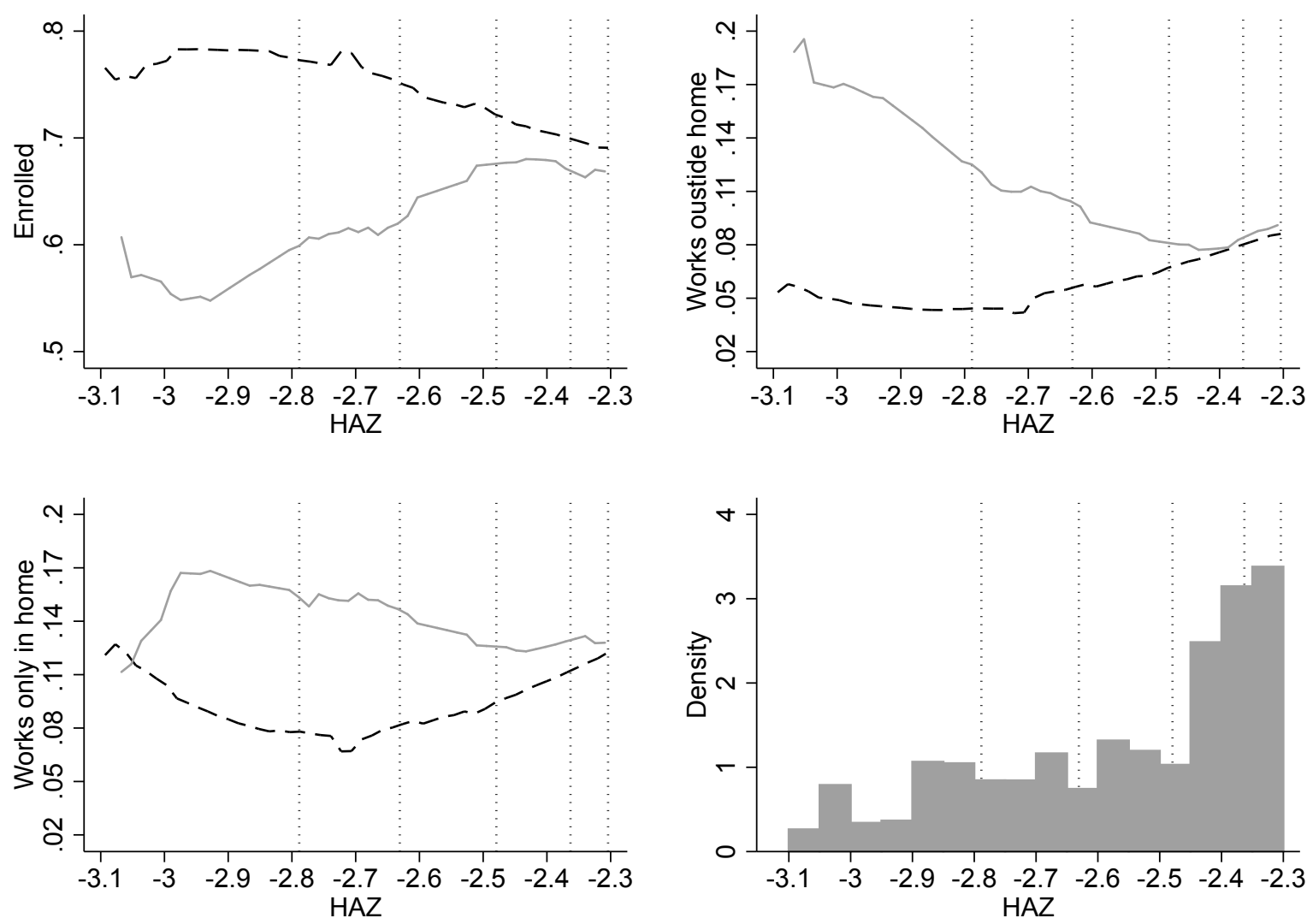

Note: Solid and dahsed lines are fitted values from local linear regressions of the $\mathrm{y}$-axis variable on the $\mathrm{x}$-axis variable (bandwidth $=0.3$; rectangular kernel). The dashed line refers to the sample of eligible children in G1 and G2, and the solid line to eligible children in G3 and G4. Dotted lines divide the 5 experimental blocks. The histogram applies a bin-width of 0.05 to the sample of eligible children. 
Figure 4: Discontinuities in sample of children eligible for the education transfer
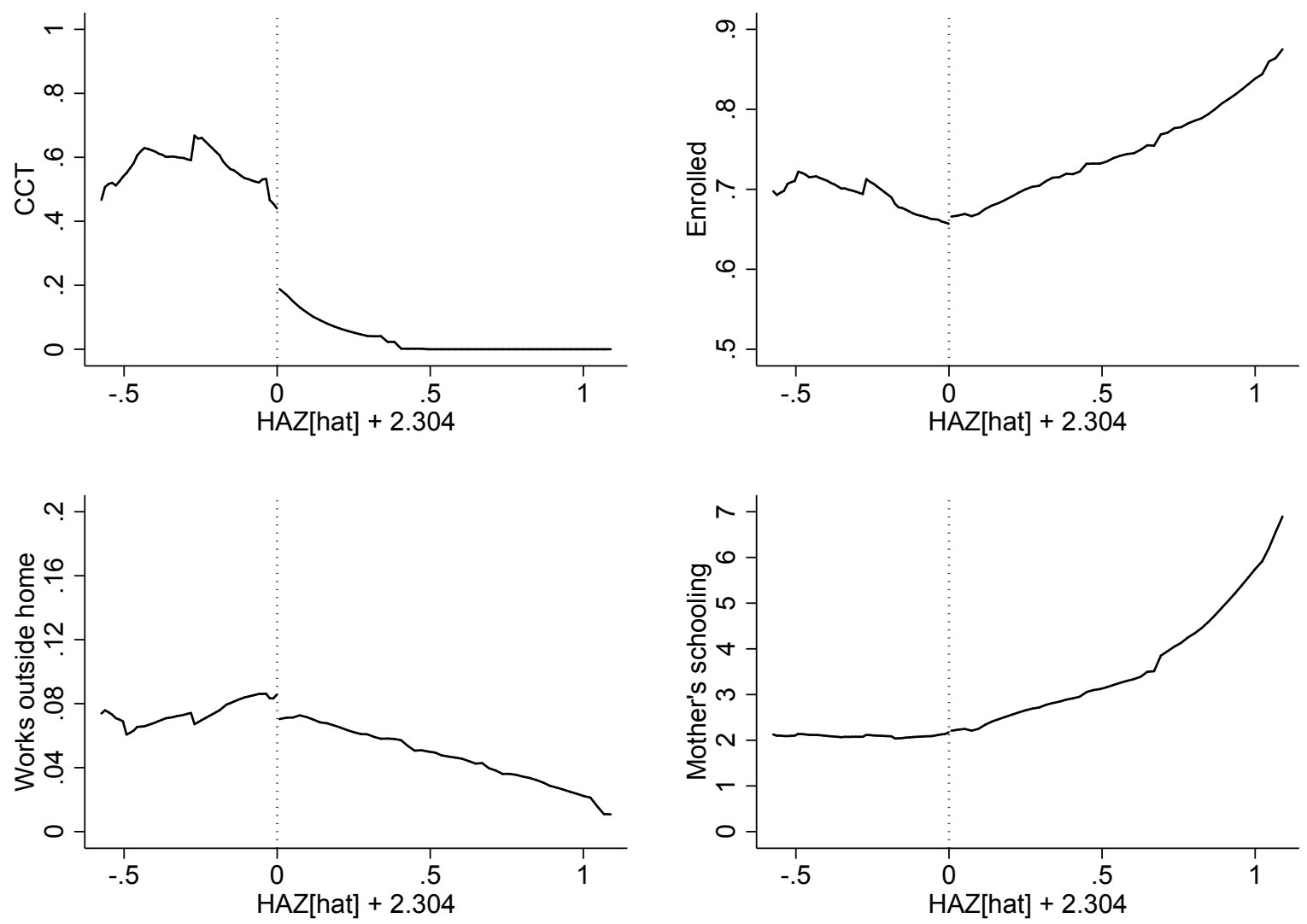

Note: Solid lines are fitted values from local linear regressions of the $\mathrm{y}$-axis variable on the $\mathrm{x}$-axis variable (bandwidth $=0.3$; rectangular kernel). Dotted lines indicate the cutoff for inclusion in the experimental sample (see text for details). 


\section{Appendix A: Supplementary Table}

Table A.1: Variable definitions

Variable definition and census form question(s) used to construct variable

\begin{tabular}{|c|c|}
\hline \multicolumn{2}{|l|}{ Dependent variables } \\
\hline Enrolled in school & $1=$ Enrolled in school on census date; $0=\operatorname{not}(\mathrm{F} 8)$ \\
\hline Works outside home & $\begin{array}{l}1=\text { Worked during past week, including self-employment, family business, } \\
\text { and agricultural work; } 0=\text { not (F12, F13A01-04); only reported for ages } 7 \\
\text { and up. }\end{array}$ \\
\hline Works only in home & $\begin{array}{l}1=\text { Worked during past week, exclusively on household chores; } 0=\text { not } \\
\text { (F13B10). Variable only reported for ages } 7 \text { and up. }\end{array}$ \\
\hline \multicolumn{2}{|l|}{ Independent variables } \\
\hline Age & Integer age on census date (F3). \\
\hline Female & $1=$ Female; $0=$ Male $(\mathrm{F} 2)$ \\
\hline Born in municipality & $1=$ Born in present municipality; $0=\operatorname{not}(\mathrm{F} 4 \mathrm{~A})$. \\
\hline Lenca & $1=$ Lenca; $0=\operatorname{not}(\mathrm{F} 5)$ \\
\hline Other & $1=$ Other non-mestizo ethnicity/race (Garífuna, etc.); $0=$ not (F5). \\
\hline Father is literate & $1=$ Father is literate; $0=\operatorname{not}(\mathrm{F} 7, \mathrm{~F} 1, \mathrm{~F} 2)$ \\
\hline Mother is literate & $1=$ Mother is literate; $0=\operatorname{not}(\mathrm{F} 7, \mathrm{~F} 1, \mathrm{~F} 2)$. \\
\hline Father's schooling & Years of father's schooling (F9, F1, F2). \\
\hline Mother's schooling & Years of mother's schooling (F9, F1, F2). \\
\hline Dirt floor & $1=$ Dwelling has dirt floor; $0=\operatorname{not}(\mathrm{B} 5)$ \\
\hline Piped water & $1=$ Dwelling has piped water from public or private source; $0=$ not $(\mathrm{B} 6)$ \\
\hline Electricity & $\begin{array}{l}1=\text { Electric light from private or public source; } 0=\text { light from another source } \\
\text { (ocote, etc.) (B8). }\end{array}$ \\
\hline Rooms in dwelling & Number of bedrooms used by household (C1). \\
\hline Sewer/septic & $1=$ Household has toilet connected to sewer or septic system; $0=$ not $(\mathrm{C} 5)$. \\
\hline Auto & $1=$ Household has at least one auto; $0=\operatorname{not}(\mathrm{C} 7)$ \\
\hline Refrigerator & $1=$ Household has refrigerator; $0=$ not $(\mathrm{C} 8 \mathrm{a})$ \\
\hline Computer & $1=$ Household has computer; $0=$ not $(\mathrm{C} 8 \mathrm{~g})$ \\
\hline Television & $1=$ Household has television; $0=\operatorname{not}(\mathrm{C} 8 \mathrm{e})$ \\
\hline Mitch & $\begin{array}{l}1=\text { at least } 1 \text { household member emigrated after Hurricane Mitch in } \\
\text { October 1998; } 0=\operatorname{not}(\mathrm{E} 1) \text {. }\end{array}$ \\
\hline Household members & Total individuals residing in household. \\
\hline Household members, 0-17 & Total individuals, ages $0-17$, residing in household. \\
\hline
\end{tabular}

Notes: The Honduran census form is available at

http:/unstats.un.org/unsd/demographic/sources/census/quest/HND2001es.pdf 